\title{
Implementing Culturally Relevant Teaching in the Classroom
}

\author{
Awilda Hernandez1, Kathryn Burrows ${ }^{2}$ \\ ${ }^{1}$ Concordia University Wisconsin, Mequon, WI, USA \\ ${ }^{2}$ Portland State University, Portland, OR, USA \\ Email: hernandez.awilda07@gmail.com, Kburrows@pdx.edu
}

How to cite this paper: Hernandez, A., \& Burrows, K. (2021). Implementing Culturally Relevant Teaching in the Classroom. Open Journal of Leadership, 10, 338-363. https://doi.org/10.4236/ojl.2021.104020

Received: October 31, 2021

Accepted: December 18, 2021

Published: December 21, 2021

Copyright (c) 2021 by author(s) and Scientific Research Publishing Inc. This work is licensed under the Creative Commons Attribution International License (CC BY 4.0).

http://creativecommons.org/licenses/by/4.0/ (c) (i) Open Access

\begin{abstract}
Culturally, Relevant Teaching (CRT) focuses on academic success for all students, cultural competencies, and sociopolitical aspects and has been proven effective among school cultures that are diverse in demographics. As schools become increasingly diverse, there is a greater need for effective education for the entire classroom while also meeting the specific needs of culturally diverse student groups. This study focuses on how in-service teachers' implement $\mathrm{CRT}$ in high school classrooms. Interviews with 20 in-service teachers across eight states revealed five themes: Class environment under a Culturally Relevant Teaching approach, Culturally relevant materials, Culturally Relevant Teaching Projects, Culturally Relevant Teaching strategies and Teacher-student relationships and Culturally Relevant Teaching. This paper explores those five themes to reveal how CRT is implemented in real-world classrooms.
\end{abstract}

\section{Keywords}

Culturally Relevant Teaching, Diversity, Classroom Strategies, Socioeconomically Deprived Students of Color

\section{Introduction}

Every teacher faces diversity in the classroom. Diversity comes in many forms and can include a student's economic status, abilities, gender, religion, and culture (Valeriu, 2017). Teachers are faced with mandated learning standards that must be taught in a manner that can benefit all students. According to the $\mathrm{Na}$ tional Association for Education Statistics (McFarland et al., 2018), elementary and secondary school enrollment increased from 47.2 million in 2000 to 50.4 million in 2015. Not only has there been a significant rise in enrollment, but there has also been a significant shift in demographics (McFarland et al., 2018). 
White student enrollment decreased from $61 \%$ to $49 \%$, Black student enrollment also dropped from $17 \%$ to $15 \%$, Hispanic students saw an increase from $16 \%$ to $26 \%$, and Asian/Pacific and students identified as having two or more races increased by $1 \%$. Teachers should adapt their teaching methods to reflect the shift in the school demographics.

The shift in diversity is not limited to the United States; the shift in diverse populations has been recognized globally (Forghani-Arani, Cerna, \& Bannon, 2019). Forghani-Arani et al. (2019) write that diverse education constitutes "characteristics that can affect the specific ways in which developmental potential and learning are realized, including cultural, linguistic, ethnic, religious and socio-economic differences" (p. 7). As diversity in education is a topic of importance within the United States (Hodge \& Collins, 2019), many studies have focused on teaching qualities and competencies that are effective in diverse classroom settings (Forghani-Arani et al., 2019).

Culturally relevant teaching (CRT, also referred to as culturally relevant pedagogy) has a focus on academic success for all students, cultural competencies, and sociopolitical concerns, and has been proven effective among school cultures that are demographically diverse (Hodge \& Collins, 2019). As schools are becoming more diverse, there is an increased "need for providing education that serves the needs of all students as well as the unique needs of particular individuals or subgroups becomes even more important" (Wachira \& Mburu, 2019: p. 1). This study focuses on how in-service teachers' implement CRT in high school classrooms.

This paper will first provide background on CRT and will then explain the purpose of the study. Then, we present the literature review, which will focus on the achievement gap between native and culturally diverse students and implementing CRT in the classroom. We will then describe the sample and our research methods and analysis techniques. We then present the findings, and conclude the paper with a discussion, including limitations of the current study and implications for policy and practice.

\subsection{Background}

CRT was created from a critical question of Ladson-Billings (1990). Instead of asking what was wrong with minority students concerning their abilities to learn, Ladson-Billings changed the face of educational pedagogy by asking what was right with minority students. By researching methods that were working effectively in diverse classrooms, Ladson-Billings was able to identify ways to improve teacher education. The researcher identified three major domains of teaching that could be used in various diverse settings. The three domains of educator practice include "academic success, cultural competence, and sociopolitical consciousness" (Ladson-Billings, 2014: p. 75). In CRT, teachers work with students to help develop skills that are necessary for educational success and diversity is valued within the classroom. Teachers who practice CRT help support the aca- 
demic success and personal growth of every student.

Culturally relevant teaching is most effective when supported by educational administration. Implementation needs monetary support and leadership encouragement. Flores (2018: p. 345) indicated that during the last couple of decades, the elevated federal and state accountability policies have further underscored and communicated how public K-12 educational institutions have struggled to improve the educational achievements of black and Latina/o students. Administrators are the educational leaders that many educators look to for support. Flores (2018) emphasized how this can impact schools and encouraged CRT as a means for administration to provide support and opportunities for educators to introduce cultural integrity in schools through critically analyzing laws, policies, and procedures. Support of CRT, especially within diverse school populations, is critical to effectively incorporate this teaching approach.

There are a few organizations that specialize in educational materials that promote utilizing CRT. Change Kids Lives (2019) offer advice and academic articles that support CRT and their websites also offer links to resources that can support teachers with implementing CRT strategies into their lesson planning. Workbooks that offer guidance, resources, supporting literature, and relevant websites would be beneficial for any school system. The more educators have access to support for CRT, the more effective their classrooms can be.

\subsection{Purpose of the Study}

Through the lens of a culturally relevant pedagogy theoretical framework, the purpose of this qualitative research study is to explore how in-service teachers implement CRT in the classroom. Bonner, Warren and Jiang (2018) indicated that diverse student populations benefit from a CRT teaching approach as this form of teaching encourages the importance and success of every student. CRT practices that are implemented in diverse settings have been found to make a positive impact on student engagement (Vescio, 2016). Researchers Bonner et al. (2018) found that teachers who committed to CRT had strong efficacy within their diverse classrooms and were more likely to anticipate positive learning outcomes by addressing the diverse needs of their students. Understanding the perspectives of educators that teach diverse populations can help future educators and researchers develop effective implementation strategies of CRT that are beneficial to the school, classroom, and students. The research question that enlivens this research is: How do in-service teachers implement CRT in the classroom?

\section{Literature Review}

CRT has been used by many educators as a strategy to empower students and influence their learning (Ladson-Billings, 2014). By understanding the basis of a culturally relevant pedagogy, educators will have a better understanding of biases that may exist when teaching in a diverse classroom (Brown-Jeffy \& Cooper, 
2011). This literature review will dive into CRT, identifying and closing the achievement gap between white and racially diverse students, implementing culturally relevant teaching in the classroom, and how, as the years progressed, new methods for teaching diverse classrooms were necessary.

Many studies have been conducted exploring the effects of CRT as it is applied to the classroom learning environment (Christ \& Sharma, 2018; Larson et al., 2018; Lowery, 2018). In a study by Larson et al. (2018), researchers examined the relationship between classroom behaviors and the use of CRT. Researchers found a significant correlation between observations of CRT and proactive practices to manage behavior (Larson et al., 2018). In another study, Christ and Sharma (2018) explored text selection in relation to CRT. The researchers were able to identify the challenges and successes of teachers who were trying to implement CRT within their classrooms. From their research, they identified four challenges in implementing CRT: "resistance, limited view of culture, lack of knowledge about students' cultures and identities, and lack of opportunities for students to develop critical consciousness" (p. 55). They also identified three areas of success for educators implementing CRT: teachers should be knowledgeable about the culture and identity of their students, attention should be paid to the various dimensions of literature used in the classroom, and text selection and pedagogy should be a culturally relevant combination. CRT has been found to be effective in promoting a positive and effective classroom learning environment; however, the implementation may not be successful without the support of administration (Lowery, 2018).

\subsection{Achievement Gap}

Addressing the achievement gap among students who come from ethnic or culturally diverse backgrounds is a concern that requires immediate attention (Brown-Jeffy \& Cooper, 2011). United States classroom demographics continue to shift as most of the student body becomes more ethnically diverse (King, McIntosh, \& Bell-Ellwanger, 2016).

Murnane (2007) argued that children living in poverty are more likely to leave school without the necessary skills to earn a decent living in our ever-changing economy. Several researchers affirmed that these children tend to be disadvantaged, dis-privileged, and oppressed (Dozier, Johnston, \& Rogers, 2006; Janks, 2010; Kuby, 2013; Murnane, 2007). These children typically face many systemic barriers which can grossly impact their lives causing a delay, regression, or tragic end to their overall academic, financial, and social success. Some of these barriers include: being treated as denizens rather than citizens, being paid lower wages, being denied equal access to education and health care, being racially profiled, and being violently attacked and/or killed by police officers.

An academic achievement gap is usually thought to be the disparities found in test scores between Whites, minorities, and low-income students (Musu-Gillete et al., 2016; NEA, 2018). Since 2000, the Hispanic population has grown at a rate 
of $2 \%$ to $3 \%$ each year, whereas the Caucasian population has decreased by $10 \%$ every five years. The Hispanic/Latino population is growing at a rate that is indirectly proportional to that of Caucasian Americans, a trend that is observed every five years. The Hispanic/Latino population grows at a rate that is indirectly proportional to that of the Caucasian population. In other words, the Hispanic/Latino population increases while the Caucasian population decreases.

Academic achievement gaps exist between the predominantly White student body and several other student groups including racial and ethnic minorities, English language learners (ELL), students with disabilities, between genders (male vs female), and students from low socioeconomic status backgrounds ( $\mathrm{Mu}-$ su-Gillete et al., 2016; NEA, 2018). Further, achievement gaps are not just indicative of the disparities found in test scores (Scholastic Assessment Test [SAT], American College Test [ACT], statewide standardized tests, etc.), but also by the availability of opportunities (advanced placement courses, higher education), and overall student attainment (high school graduation rates, college attendance and graduation rates, employment: Musu-Gillete et al., 2016; NEA, 2018).

Closing the academic achievement gap among minority students is complex and requires a complete transformation as opposed to transactional reform. Colgren and Sappington (2015) analyzed English ACT scores for minority students in English advanced placement (AP) classes against White and non-low-income students. The researchers found that minority students in AP English classes performed at the same level as White students who did not attend AP classes. Furthermore, when comparing minority and White students in AP courses, the researchers found White students significantly outperformed their minority counterparts.

\subsection{Closing the Achievement Gap: Applying CRT in the Classroom}

Based on research findings, it is evident that the academic achievement gap in minority students exists and is maintained and perpetuated by traditional school constructs (Anthony-Stevens et al., 2017; Banerjee, 2018; Gershenson et al., 2018; McFarland et al., 2018; NEA, 2018). CRT strategies are proposed to be a solution (Lopez, 2016). The next part of this literature review will examine how in-service teachers apply CRT strategies within the classroom; and how the application of strategies affects student achievement and behavior (Anthony-Stevens et al., 2017; Banerjee, 2018; Gershenson et al., 2018; Holt \& Gershenson, 2015; Lindsay \& Hart, 2017).

A correlational study conducted in 2016 proposed to examine the relationship between the implementation of CRT strategies within the classroom and its effect on student behavior and achievement in obtaining reading milestones within the Latino student population (Lopez, 2016). Research findings suggested a positive correlation between the implementation of CRT strategies and student outcomes (increased reading scores). Teachers reported a strong belief that the application of CRT strategies within the classroom had students with the highest 
increase in reading scores by the end of the year. A total of 244 students in third to fifth grade participated as well as 16 teachers. Achievement outcomes were measured by the collection of test scores from a standardized test used by the state to assess reading benchmarks. Hence, the research findings suggest a link between the implementation of CRT strategies and positive student outcomes.

Similarly, a quantitative study conducted in 2016 focused on students' perceptions of their teachers' use of CRT strategies within the classroom (Byrd, 2016). Researchers surveyed students on their instructor's constructivist teaching practices and cultural engagement, specific measures of school racial socialization, academic outcomes, and racial attitudes. Participants consisted of a random sampling of 315 students from the age of 12 to 18 years old using an online survey. Research findings suggested a positive association between greater academic outcomes, constructivist teaching practices, and promotion of cultural competence. Specifically, students reported being more interested in school and having a greater sense of belonging when instructors used constructivism (use real-life examples, videos, pictures, guest speakers as teaching tools) teaching practices and could learn more about their own heritage and culture at school (racial socialization). Hence, research findings suggest a positive association between CRT strategies and academic outcomes as it relates to promotion of cultural competence and teacher's constructivist practices. Researchers concluded that constructivist practices allowed students to become comfortable within their surroundings thereby facilitating a higher level of engagement and peer connection. Ultimately, this teaching practice facilitated intergroup relations and reduced prejudice within the classroom.

Finally, a quantitative study conducted in 2017 found a positive association between implementation of CRT strategies and proactive behavioral management (PBM) within the classroom resulted in increased student engagement and positive behavior (Larson et al., 2018). Participants consisted of a total of 274 teachers ( $86 \%$ female, $80 \%$ white, $47 \%$ middle school teachers) from 18 different schools located in the same school district. The district was located in both urban and suburban areas. Researchers employed structural equation modeling (SEM) to analyze their findings. Research findings from this study provided evidence that CRT strategies increase student engagement and when used in conjunction with PBM, can help to augment biases in discipline practices of minority students. Researchers analyzed the observed behaviors of students and teachers within 248 classrooms against several self-reporting surveys. Researchers wanted to explore the relationship between teachers implementing PBM and CRT strategies and their effects on student engagement and positive behavior.

\subsection{Implementing CRT Strategies in the Classroom}

Although a great deal of research has been conducted on why CRT and Culturally Relevant Pedagogy are important and on in-service teachers' perceptions of it, very little research has examined how teachers implement it within the classroom (Brown-Jeffy \& Cooper, 2011; Lambeth \& Smith, 2016). A study con- 
ducted in 2017 examined the teaching practices of seven award winning teachers at an urban school in the southeast region of the United States (Farinde- $\mathrm{Wu}$, Glover, \& Williams, 2017). The qualitative study used in-depth, open-ended, semi-structured interviews to assess in-service teacher practices (Farinde-Wu et al., 2017). In-service teachers were asked how they built rapport and engaged students on a daily basis and four major themes emerged among the seven interviews. First, the in-service teachers all implemented RACCE (show respect, act immediately, communicate, celebrate, and encourage students) within their classrooms. Second, they all worked closely with students to create a "familial-style classroom culture of success" (p. 287). Thirdly, the in-service teachers established "student-first" learning wherein the students were central to all learning processes. Finally, each of the in-service teachers integrated, "critical multicultural views and perspectives within the classroom" (p. 291).

Another qualitative study conducted in 2017 analyzed the teaching strategies of 12 Hispanic pre-service teachers in their last semester of school and practicum training (Hernandez \& Shroyer, 2017). Using a CRT framework, researchers concluded that the participants successfully implemented four out of the five CRT framework elements used for analysis in this study. Specifically, pre-service teachers were able to successfully integrate culturally relevant content from many cultures within their math and science curriculum. Further, they fostered positive teacher-student relationships and had high expectations for every student regardless of ethnic/racial background. Second, knowledge construction was successfully facilitated by building on students' prior knowledge thereby building links between student's experiences (at home and in the community) and the curriculum being taught. Third, pre-service teachers were able to reduce prejudice by using elements of the environment to form collaborations with the students and their parents. For example, using a student's native language in class to instruct or speak with their parents in their native language. By incorporating contextual factors (elements of the environment for collaboration), pre-service teachers were able to create a safe learning environment in which students felt comfortable participating in discussion and instruction. Finally, pre-service teachers were able to create developmentally appropriate learning opportunities within the classroom thereby facilitating academic development.

A qualitative research study conducted in 2018 examined how novel technology could be used as a strategy of CRT to connect students' home lives with school (Mackay \& Strickland, 2018). A teacher at a diverse urban middle school attempted to connect to students through the application of an iPod assignment in which the students were allowed to take the device home and introduce the teacher to whomever they felt relevant through their video recording. Research findings indicated a successful connection can be made between home and school contexts using technology to reveal relationships within the students' lives that matter, as well as defining what the student finds relevant within their own lives. The research findings illustrate how introducing the context of a student's home life can create an interaction between teacher and student that facilitates instruc- 
tional relevance within the classroom. Hence, the findings of this study offer support to the relevance of implementing CRT strategies within the classroom through a joint venture between teacher and student.

\section{Methods}

This study's population was in-service high school teachers working at a public-school district and teaching in a high school that serves students in grades 9 through 12. Teachers' school districts were located in various parts throughout the United States. Participants taught in New Jersey, New York, Washington State, South Carolina, Illinois, Utah, Arizona, and New Mexico. Teachers were through the presence of teaching professional groups on Facebook. Participants who serve diverse student populations volunteered for the interviews.

Semi-structured interviews were used (see Appendix A). I first asked demographic questions concerning gender, age, teaching experience, and ethnicity, and then more open-ended questions that were focused on Culturally Relevant Teaching (CRT) practices in the classroom. This study's population was in-service high school teachers working at a public-school district and teaching in a high school that serves students in grades 9 through 12. Teachers' school districts are located in various parts throughout the United States. Participants taught in New Jersey, New York, Washington State, South Carolina, Illinois, Utah, Arizona and New Mexico. Participants consisted of multidisciplinary in-service high school teachers who instructed on a variety of subjects that include English, American History, Music, Mathematics, English as a Second Language, Science, Technology, Engineering and Mathematics (STEM), Western Civilization, and Civics and Government. The total number of participants was 20.85 percent of in-service teacher participants were female, and 15 percent were male. 30 percent of female participants identified themselves as Latina or Hispanic while the remainder 70 percent identified themselves as White or Caucasian. 100 percent of the male participants identified themselves with at least one of these groups: White or Caucasian, Jewish descent, and Asian. Teachers varied in experience from recently hired to well-seasoned professionals with many years of classroom teaching experience. 29.41 percent of participants have 1 - 10 years of teaching experience. 64.70 percent of participants have $10-20$ years of teaching experience, while 23.52 percent of participants have 20 - 30 years of teaching experience. The age ranges were 21 - 69. 11.76 percent were ages 21 through 29. 29.41 percent were ages 30 through 39. 41.18 percent were ages 40 through 49.29 .41 percent were 50 through 59 while 5.88 percent were 60 through 69 . Although the interviews yielded a wealth of information about a variety of issues related to CRT, this paper will focus exclusively on the theme, "How teachers work in the classroom following a CRT approach (including classroom strategies)."

\subsection{Description of the Sample}

Thirty in-service high school teachers volunteered to participate in this study; 
however, I reached data saturation on the 20th interview, therefore, only twenty interviews were completed. I determined that I had reached data saturation because no new information was being provided in the interviews-each respondent was giving the same answers. I was unable to learn anything new from in-service teachers at high schools. When I finished interviewing the final four people, it became clear to me that I had achieved data saturation. Each participant was provided the research study consent form before the phone interviews were scheduled and conducted. The researcher identified each participant with a number and listed participants by order of interview scheduled time and date. Phone interviews were conducted at the beginning of the 2020 school year and were completed prior to the Covid school closures.

I identified and selected study participants from teacher organizations on social media who met the selected criteria that they must be an in-service high school teacher at a public school in a high school that serves students in grades nine through twelve. In order to recruit for the study, I searched Facebook for professional teacher groups and asked group moderators whether I could recruit from their community. Many groups were hesitant to let me recruit and were worried that their schools or school districts would discover they had said "negative" things about their schools. Convenience sampling was employed to procure participants (Etikan, 2016), so the results are not generalizable outside of this particular sample.

Participants consisted of multi-disciplinary, in-service high school teachers who instructed various subjects including English, American History, Music, Mathematics, English as a Second Language, Spanish Language, Western Civilization, Civics and Government, and STEM. 85\% of participants were female. The academic background of the participants included bachelor's degrees and master's degrees in education. Participants' professional experience ranged from two to thirty years of teaching experience. Each teacher participant was from a different school. Thus, various school districts throughout the United States were represented, including student classroom populations from urban and suburban locations. Participants taught various students from diverse backgrounds, including undocumented students, from Europe, Asia, South and Central America, and the Middle East. Students represented diverse socio-economic, lifestyles, and special needs, including homeless students, LGBTQ+ students, all-White student classrooms, Navajo nation students, and students with physical and mental disabilities.

\subsection{Research Methodology and Analysis}

I used NVivo, a computer-assisted qualitative data analysis software (CAQDAS) program, for the data analysis. NVivo is an analysis program that allows researchers to code transcripts and has also been recommended by several scholars (Maher, Hadfield, Hutchings, \& de Eyto, 2018; Zamawe, 2015). This tool was effective in helping identify themes that emerged based on interview responses. 
Once the Concordia University-Portland chair committee, and the Concordia University-Portland Institutional Review Board (CU IRB) approved the research proposal, participants were recruited and invited to participate in the study. When Facebook group participants indicated to me that they were interested in participating in the study, an email was sent requesting a time and date to conduct the phone. An interview guide (see Appendix A) was used that was based on, and aligned with, the guiding research question. I requested that each participant provided proof of their teaching status and I verified the teacher's credentials.

\subsection{Identification of Themes}

Emergent coding was applied. Emergent coding consists of the identification of themes originating from the data collection (Stuckey, 2015). Thematic Analysis was used to work with the data. According to Maguire and Delahunt (2017), “Thematic Analysis is the process of identifying patterns or themes within qualitative data" (p. 3352).

A Thematic Analysis consists of two stages: 1) the codification stage, where data is approached and receives a specific meaningful tag, and 2) the sub-theme stage, where the different codes are grouped under a meaningful sub-theme.

According to Chenail (2012), undivided units of qualitative significance are the incidents found in the interviews; the name for the qualitative differences becomes the code.

I codified the second interview using the same codes as the first, even though additional codes were created, if necessary. This stage is important because the researcher should not overlook any important event mentioned by participants in the interviews. After fifteen interviews were analyzed, the researcher studied and reviewed the codes as a second step to make sure that the codes fit well in the overall picture of the data.

According to Leech and Onwuegbuzie (2007) and Glaser (1965), the fathers of grounded theory, I used the method of constant comparison analysis. When a researcher is interested in utilizing an entire dataset to identify underlying themes presented through the data, a constant comparison analysis can be helpful. Constant comparison can be undertaken deductively (e.g., codes are identified prior to analysis and then looked for in the data), inductively (e.g., codes emerge from the data), or abductively (i.e., codes emerge iteratively) (Leech \& Onwuegbuzie, 2007: p. 566). The movement of constant comparison (Coghlan \& Filo, 2013; Leech \& Onwuegbuzie, 2007; Glaser, 1965) can be defined as the movement that the researcher makes when the researcher's mind goes back and forth between the data and the analysis that the researcher is developing. For the analysis to progress, it is necessary for the researcher to constantly relate this comparison between the data (the interviews) and the ongoing analysis. This movement also allows the researcher to corroborate, again and again, the codes chosen, and the themes and sub-themes created, since it is only through the codes and the categories that 
a researcher can reflect on what is happening in the data.

\section{Summary of Findings}

The research question examined in this study is how do in-service teachers implement Culturally Relevant Teaching in the classroom? The implementation of this approach calls for in-service teachers' creativity and willingness to get fully involved in their classroom. In-service teachers developed their own understanding of CRT and have had to embrace its meaning in order to implement CRT methods in class. Teachers have done this by taking into account students' culture. Furthermore, pedagogical strategies, school and class projects are also some of the practices teachers have implemented in their classrooms with the aim of reaching out to each student and their cultural differences.

\subsection{Presentation of Data and Results}

Recall the research question was: How do in-service teachers implement Culturally Relevant Teaching (CRT) in the classroom? This research question explored the dynamics of the multicultural classroom created by teachers and students. It also included teacher practices and the influence CRT framework has on students. The data collected and analyzed from the phone interviews revealed five themes, as is detailed in Table 1 below.

\subsection{The Classroom Work under Culturally Relevant Teaching Approach}

The global classroom work is developed by two main stakeholders-the teachers and the students. It includes the strategies followed by the teachers, the relationships among these actors, and the impact that CRT approach has on the students. Five themes emerged in the data analysis process.

\section{Theme 1-Class environment.}

The first theme was Class Environment under a CRT approach. It refers to the different manners in which teachers make efforts to develop a rich environment to encourage the success of every student in the classroom. Under such an environment, every student can feel comfortable and identified, given that teachers looked to create an atmosphere where students can feel identified; also, the materials, resources, strategies, and other activities developed in the classroom were designed to warrant such identification and success in every child.

Table 1. Themes emerging from the data analysis.

\section{Themes}

- Class environment under a Culturally Relevant Teaching (CRT) approach

- Culturally relevant materials

- Culturally Relevant Teaching (CRT) Projects

- Culturally Relevant Teaching (CRT) strategies

- Teacher-student relationships and Culturally Relevant Teaching (CRT) 
Some teachers talked about their classrooms' environment and their ways to interact with the students. Some of them have, as the main goal, the complete development and growth of each student, "It's really more about helping them grow as people in their education and in their social lives" (P15). To achieve this goal of full growth development, the teachers engaged in diverse ways to approach their students, for instance, one commented about the importance of building a relationship with each student, "It's all building a rapport. If the students don't respect you and you don't have a good demeanor with them, they'll never learn from you" (P11). In doing this, the teacher can open ways of communication that will be used to build trust and respect among the different students and the teacher, "For me, it starts on day one. I'm a very open person. I go over the class a little bit and then I have a questionnaire that they get to answer that there's a space on there where they, it says, "Tell me anything that will help me to be a better teacher to you." And they know that nobody else sees it, it's just me. And so, a lot of times that opens up a door of communication" (P1).

For other teachers, the classroom's environment under a CRT approach must have continuous items that remind the students that all they are welcome and all them are represented in the group, "I just try to create an environment where they recognize that we're all in this together. That I care about them, that I want what's best for them and what's best for one might not be what's best for another... It's really more about helping them grow as people in their education and in their social lives... I just try to build a sense of trust with my kids and hope that they can build a sense of trust with each other" (P15).

Other teachers commented about the great results coming from an open-door policy to approach the CRT,

In my classroom I have an open-door policy everyone is welcomed. I know a lot of students feel comfortable talking to me about things. I'm also the gay/straight alliance advisor at our school. So, not only kids of different cultures come to see me, but kids who have different sexualities also come in and see me and talk to me and I know a lot of them feel comfortable doing so" (P16).

It can be said that, in the effort to construct the best relationship with the students, the teachers focus on their backgrounds, and they develop the willingness to know each child. Notions such as equity, respect, responsibility, minorities, differences, consideration to others, and compassion are concepts/values transmitted through the teachers' attitudes and material environment and strategies developed by the teachers, "Everyone is welcome. It doesn't matter gender, race, whatever. You're all welcome" (P13).

The physical aspect of the classroom was also commented on, and teachers discussed the material they have on their walls, "I would say that my classroom and its physical appearance is very inclusive. I have international flags that are decorated around the entire classroom." (P17). Flags and posters represent an interesting material through which every student felt identified, "I also have a lot 
of posters that are in different languages and different languages that really promote. Anyone can turn their head at any moment and connect with a piece of artwork that I have framed on my walls in order to kind of elicit this idea of everyone's voice being identified here" (P17). Through these environments, it is evident for the students that all their cultural backgrounds are included. However, other types of differences, like gender and sexual orientation differences, are also represented into the classrooms' walls, "On one wall there might be an LGBTQ flag that says, "Love is love." On another wall we might have, "Stay woke," or, "Black lives matter." On another wall I have a sign that says, "Refugees welcome here." On another wall I have women's rights protesting posters" (P17).

It is remarked that under the CRT approach, it is possible to create and develop an ecosystem of mutual interchanges between students and teachers, and students among themselves. Such an ecosystem seems based on values where equality and respect are the central stones. Finally, the practice of responsible behavior is also promoted through the CRT approach. In this regard, one participant stated, "My first rule is they can do anything they want in class. They can do the work, they cannot do the work, but either way they have to accept the consequences. So, I put the responsibility in their hands by saying that their learning is a product of their work. It generally has given kids the self-agency to work for themselves" (P18). Brief, openness, inclusion, respect, responsibility are the subjacent values promoted by the classroom environment under CRT approach.

\section{Theme 2-Culturally relevant materials.}

The next theme is culturally relevant materials. The materials developed and employed by the interviewees show that they have taken into account the cultural differences and the particular tastes and preferences of the students. The majority of the teachers interviewed agreed that these materials need to be related to the students' background in such a way that they feel identified. As a consequence, students engage in the task and achieve the learning objectives. Books and novels present characters, situations, landscapes that can be easily related to the lived experiences of these students, "when I provide things that relate to them, the students are like, wow, this character sounds like me or this character minds me of myself. Or they're able to really understand it. Like for example, I don't know, one of the texts that we have an option of teaching is about baseball and I never teach that one because none of the students like it. They all want to learn about soccer. I'll just provide one about soccer instead" (P8).

"Sometimes, the district recommends the materials; it's a district wide textbook for ninth grade. Each unit, like the unit we're doing right now is called The Bond Between Us... It's about an end-of-life story for a little girl who is the victim of a volcano eruption and a reporter who has to save her life or try to save her life" (P5).

Other times, the teacher and the students talk and decide what they want to learn and how it can be adapted to the different areas of knowledge, "we have a 
lot of student voice in my classroom, so I like the students to pick a project or to get an idea of something that they connect to. So, it could even be something on television, something on Netflix, a TV show. It could be anything that's not only cultural that relates to their ethnicity, but it could be cultural that relates to their age range. I think student voice is very important. We do a lot of reflections. I do a lot of asking the students what do they want to do? What do they want to learn?" (P6).

The materials and the project-based learning promote the exchange between students in the classroom as well as with their teacher. Other teachers mentioned team-based learning as a way to use related material chosen by the students and presented as a personal assignment, "I teach in a team-based learning environment, collaborative, semi-permanent team roles. I connect the team roles to realistic work roles, like documentation, supply chain management, team lead, human resources" (P10).

The "student voices" is another interesting approach to develop the learning process by integrating material that the students themselves have selected, "I mean right now we're doing a lot of things like with the basics, like avid training or student voices. Student voice is a big one right now, that the students should get to pick what they want us to teach them. They should guide each class period" (P11).

Another example of the student voices is highlighted by P12, she stated, "I'm the advisor to our Student Voice Committee and we took a group of kids that were interested. The demographics of the group becomes strongly LGBTQ and students of color, just by the topics and by that make up, the topics have become focused more early on in the LGBTQ conversations than actually race" (P12).

Theme 3-Culturally Relevant Teaching Strategies.

The next-theme, culturally relevant teaching strategies, reveals the different ways that teachers have to teach their students. It should be noted that the teachers noted diverse approaches, like the Socratic approach or teamwork. However, for all teachers, there was a high level of student participation. For instance, one teacher commented, "I have modified different assignments to better relate to students. Sometimes if I'm coming up with an example or a problem on my own, I'll take what I know about my students and try to incorporate that into the problem... I do try to modify tasks, lessons to better suit their needs with every class that I teach. So, I don't always teach the same thing the same way twice because it really just depends on the kids in my classroom" (P15).

Another participant highlighted her strategy to teach difficult topic such as slavery or the Holocaust,

My strategy is to kind of front load warnings about making sure that the kids know that some really hard stuff is coming, but I'm there to support them in learning about it...my rule is as long as kids know that some of these stories are really hard, it's basically almost anything...you have to temper how you teach it...to be careful about how you implement it. When 
I teach my students at junior and senior level about those dark times of history, I warn them, I say some of this stuff could be really difficult, but that doesn't mean it didn't happen" (P18).

It can be said that CRT allows approaching painful realities, according to the students' characteristics. This is done without removing reality from historical facts or events. Another teacher mentioned the videos and the readings as two ways to teach her students alongside the Socratic method. This method promotes the students' participation and the expression of their opinions related to the topic. What they really think is respectfully exposed and discussed,

I guess the best strategy that I find is either videos or readings. Videos or readings that they can first annotate from their own place and then get into some type of a Socratic seminar where they. Prior to the Socratic seminar, small groups, mixed groups where they share what they were thinking and see how that influences their conversation or thoughts (P12).

An interesting strategy involved the use of a rating scale to assess the students' understanding of a specific matter in the classroom. The teacher called it "number line ratings" explaining it as follows:

one strategy that I have found appropriate for high school...is just number line ratings where we might read a piece of text with some really controversial information, controversial thinking (...) I ask the kids, on a scale from one to 10 , how much do you relate to this story, 10 being you really relate, you really understand, this really not just what you know about the world, all the way down to one, I can't even believe this was happening (P5).

This activity is followed by a general discussion, where the points of view and the students' opinions are exposed. The benefits for the students' learning process are significant, as the teacher went on to say,

We use those number line writings all the time. It really opens the kids' eyes to the different perceptions that are in the classroom. Then we will talk based upon our rating and have a class discussion. It's brought out a lot of really interesting ideas related to the kids' perceptions about how people are treated, how people perceive their world, what's going on in the world... They loved the honest conversation. I think it comes from building trust in the classroom first, which I always do (P5).

Finally, in an effort to consider the learning styles of the students, another teacher prefers the oral tradition over writing, looking to capture the students' attention and engagement,

I talked...about...using oral tradition over writing sometimes. So, that tends to be one of the things that I do a lot, and it is for many different reasons, but part of it is that my students are more likely to want to talk about something than to write about it. So, as an English teacher, trying to find ways to make sure that I can capture that knowledge or capture that con- 
versation and give them credit for kind of oral contributions. That's definitely a strategy that I use (P9).

The CRT approach favors the use and implementation of projects, a group activity where every student selects the theme and participates in the project's objectives. The teachers commented on this meaningful way to incorporate the students' backgrounds and, at the same time, teach them the concepts of the lessons.

\section{Theme 4-Culturally relevant teaching (CRT) projects}

Among the lessons, projects or special events, participants mentioned many of these events that helped them reinforce the students' knowledge under the CRT framework. Some teachers talked about the lessons they prepared, such as a lesson about the OJ Simpson trial, "Well, because I teach forensics, we do the OJ trial and that brings up a lot about race, domestic violence, racial biases, problems with the police. And that seems to help open the discussion honestly with the students" (P11). Similarly, another teacher said, "I think the only thing I could think of right now is the Día de los Muertos alter that I’ve done personally in my class before and then as a school, at our high school" (P14).

P5 stated, "I try to do that with...my own curriculum. The unit called Finding Common Ground, all about understanding everybody and figuring out how to be an individual, but also figuring out the importance of being a member of a community" (P5). Other participants commented about general events that happen in the whole school, such as the World Hijab and Black History Month, "I've helped set up a World Hijab day at our school. We have a couple students who were wear Hijabs and a couple of years ago we started celebrating World Hijab day, which is every February 1st and a lot of female students and teachers wear Hijabs to show support for the Muslim students who wear them every day" (P16). Regarding the Black History Month Agenda, P17 pointed out the significant participation of the students in this event,

I can tell you, so for Black History Month, so just this last Thursday, we had a whole event. We have what's called Town Hall at our school, and so Town Hall is a place where students are able to generate their own agenda and their own plan, highlighting some of the things that they wanted to highlight for that month or that week. So, they're the ones that generate the agenda (P17).

However, other teachers have not developed any lessons, events or projects as is the case of P13, who specifically commented on the following, "Personally, I haven't. At our school, we have the ESL and the ELL teachers who will have a night where their kiddos, where their cultures are featured whether it be through food or presentation, but personally, I have not" (P13).

Theme 5-Teacher-student relationships and culturally relevant teaching approach.

The CRT approach has implications in the building of relationships between teachers and students. In this vein, it is noticeable that teachers have developed 
abilities to show their interest in the students' lives and backgrounds, as for instance, the teacher that develops blogs and shares their content with his students. Blogs have become a place to exchange, "The blogs are a big part of that and the reason that I keep bringing back the blogs is because I can individually discuss with students their own personal thoughts, beliefs, ideas, and that helps me individually focus on what they're going through. That's the best way I can describe that" (P2).

Another teacher stated that his love for food and his interest in learning the food customs of other cultures was the bond to connect with his students.

I sometimes boil it down to food, food and music. I'm a big, big foodie chef guy. I love cooking and I love all kinds of ethnic foods and. It's weird. I develop positive relationships with a lot of my kids just centered around talking about their family's dinners and what they do for holidays... Food brings us together, religion can bring us together, song can bring us together. It's just about the things that drive, that bring us together and not force us apart, and that's how you build strong relationships around culture (P18).

Essential to building this type of relationship is the necessity of remaining humble when facing people from other cultures, as one teacher mentioned it,

I think part of it is learning not to make assumptions and to realize that in some ways that I'm still learning as well. And seeing students as individuals, helping them in that, helping them to grow. It means understanding that we all come from a different place. With students I say each of them is going to have a different situation, and that I need to make sure that I check my assumptions at the door and do what I can to continue to be learning (P19).

It is notable that teachers also become learners like their students, sharing similar problems and everyday situations. Another teacher said, "Creating those relationships has also allowed me to then work with maybe some of the most, what they would consider to be challenging students, because there's a genuineness and there's just a connection that the students know that I understand" (P17).

\section{Discussion and Conclusion}

Incorporating the multicultural perspectives of CRT is essential to creating a supportive, student-centered approach that reflects minority students and students of diverse backgrounds (Hernandez \& Shroyer, 2017). This qualitative research study examined the perspectives of in-service high school teachers who teach in public school districts concerning strategies in the classroom that serve culturally diverse student populations.

The research study addressed the following questions:

How do in-service teachers implement CRT in the classroom?

Culturally relevant teaching is a mechanism that can help both academic in- 
stitutions and students adapt to diverse needs. This framework supports teachers and strengthens their commitment and understanding of students, encouraging them to thrive in their learning. Promoting cultural competencies through human interaction and relationship building can help increase minority students' academic performance, their interest in the class, in addition to creating a higher sense of unity (Byrd, 2016; Hernandez \& Shroyer, 2017; Lopez, 2016). Student participation is a key component of effective teaching. Student participation emerges through teachers' efficient training and planning to implement interest in their lessons. The U.S. educational system has faced profound disparities. Schools across the nation have also struggled to find the right practices and methods to educate diverse student groups. The U.S. educational system has struggled because the demand for well-trained teachers continues to increase. Classroom teachers are expected to diversify their lessons, even though many well-qualified teachers only received basic classroom training and receive minimum pay for their efforts (Sutcher et al., 2016). In other words, when the demand is high, and the supply is low, the lack of well-trained in-service teachers will persist, negatively impacting classroom instruction and student academic achievement.

The findings from this study provide valuable insight to addressing the achievement gap among students who come from ethnic or culturally diverse backgrounds (Brown-Jeffy \& Cooper, 2011). In response to the need to include diverse connections in the classroom, CRT strategies were created to impact students in every aspect of life (political, social, emotional, and intellectual) while offering educators a way to connect with students (Harding-DeKam, 2014; Nasir, 2002). Overall, the educators seemed passionate about their career and expressed a love of teaching. Many participants expressed feelings strongly about their school and the success of their students. As educators, they are responsible for influencing their students and helping their students reach educational goals.

CRT has been proven to be an effective means to creating an inclusive and effective learning environment in which all students feel connected and celebrated. Support in resources and training can help educators who are unfamiliar with CRT learn the benefits of the educational approach and provide teachers with the materials needed to support diverse learning in the classroom. Resources may come in the form of books and novels that celebrate characters of different cultures, religions, or lifestyle choices. Posters that celebrate diversity could also be visual aids that promote a feeling of community in the classroom. Teacher resources are also important, so that each educator knows how to pull resources to make each lesson unique and meaningful to all students.

Pappamihiel and Moreno (2011) noted that CRT strategies require educators to become aware of their students' diversity (culture, religion, or gender) to help students achieve their highest academic potential by incorporating a CRT culture into the classroom environment. Despite a lack of participants who could define CRT, many of the participants were familiar with the concept and had some ideas on how CRT is used to improve the classroom environment. This 
recognition is important because, as Vescio (2016) stated, the primary foundation of CRT is for educators to become cultural bridge builders between a student's prior cultural knowledge and what is being taught in the classroom.

Many of the participants interviewed understood how support from administration and the district could help them apply CRT into classroom' activities. This supports the findings of past researchers, who noted CRT strategies are transformational and incorporate teaching mechanisms that promote success among diverse student populations while also supporting their cultural and religious identities (Harding-DeKam, 2014; Nasir, 2002). Researchers have also supported how implementing CRT strategies can help minimize the achievement gap among minority students (Shevalier \& McKenzie, 2012).

Many participants shared they could have continuous support that reminds students all are welcome and all represent their learning community. This supports the findings of other researchers that have reported CRT has proven to be effective academically and has the power to promote students' social and emotional development (Byrd, 2016; Larson, Pas, Bradshaw, Rosenberg, \& Day-Vines, 2018). Brown-Jeffy and Cooper (2011) shared that when educators acknowledge each student's individuality, educators may help prevent racism being preserved culturally, while changing the current social atmosphere.

\subsection{Limitations}

This research study aimed to interview several in-service educators using teacher organizations platforms on social media. Availability was a limitation as in-service teachers had a busy classroom schedule, scheduled breaks, and limited time during the day to participate in the study. The sample size of 20 teacher participants was large, even though the sample was limited to in-service high school teachers at a public district. The majority of participants were familiar with Culturally Relevant Teaching (CRT) and how to apply it in their classroom practices. However, out of the 20 participants, only five understood CRT and how it is applied in the classroom. These participants provided in-depth information while other participants acknowledged that they did not use CRT in their classrooms, noting awareness of it.

The data was collected using teacher organization platforms. This recruiting method generously expanded the pool of multidisciplinary participants even though the recruiting process started at the beginning of the school year, and teachers were still in session at their prospective institutions.

\subsection{Implications of the Results for Policy and Theory}

There are implications from this study for current practices, including adding resources within special education classrooms and adjusting the instructional practices of teachers in locations of high diversity. The results of this study identified that the perceptions of the educators interviewed varied based on their understanding of CRT and the support they received from their district. 
The participants that had worked at the schools that support CRT were aware of the support and relationships needed with diverse student populations. Most of the participants were aware of CRT, however, many of the participants reported a need for support and training to successfully implement CRT practice. School administrators should consider advocating for support, training, and resources to accommodate the implementation of CRT in schools with a diverse population.

1) Policy. Many of the participants understood that policies and procedures were needed to garner the support for CRT implementation. This would ensure students of diverse ethnicities, religions, and lifestyles feel included and accepted. Federal and state policies continue to change to support the success of students, and more research on the benefits of CRT may help policymakers recognize a need for supporting the implementation of district and statewide policies.

2) Theory. The results of this study suggest that educators find value in using CRT with students from diverse backgrounds. The conceptual basis for this study was CRT. Based on recognizing a need for supporting and including the diverse needs of all students, Ladson-Billings (1994) shared CRT as learning that empowers students, challenges them socially, emotionally, and politically. The findings from this study support the three foundations of CRT. The three components are academic achievement, cultural competence, and sociopolitical consciousness. The majority of the participants shared how CRT improves student involvement, feeling connected to the learning community, and creates a sense of belongingness.

\subsection{Recommendations for Future Research}

This study did not address the issue of CRT in the primary grades that could assist in effective and meaningful educational practices. Future research should examine the CRT experiences and support of primary grade educators. For a deeper and more reliable data collection, it is recommended to recruit participants who have acquired the knowledge, training, and skills necessary to teach using culturally relevant teaching methods. When teachers understand the benefits of using CRT in their classrooms, this can be achieved through their participation in career development courses, which would allow in-service teachers the opportunity to teach students better, especially diverse student groups.

An in-depth study based on in-service teachers' experience using Culturally Relevant Teaching (CRT) classroom practices is recommended for future study to explore diverse student success further. Teachers' involvement in students' academic success is vital. It is similarly important to conduct research on in-service teachers' perspectives on CRT practices in the classroom at other specialized schools to explore the best CRT practice in helping minority student groups learn. Minority student groups need classroom instruction with an emphasis on CRT practices. Implementing a curriculum that emphasizes CRT can help stu- 
dents achieve higher academic goals and acquire learning skills that allow students to become better prepared as their learning progress becomes effective. The findings suggest that encouraging learning outcomes among students, including increased awareness of biases and prejudices and stigmas, enhances understanding of cultural differences, including diverse groups and cultures, qualities and strengths, and creates confidence and competence to engage and connect different student communities (Vesely et al., 2017).

Extensive research has conclusively demonstrated that children's social class is one of the most significant predictors-if not the single most significant predictor-of their educational success. Moreover, it is increasingly apparent that performance gaps by social class take root in the earliest years of children's lives and fail to narrow in the years that follow. That is, children who start behind stay behind-they are rarely able to make up the lost ground. Future research may be able to identify and explain teachers' cultural competencies in early education by focusing issues relating to teachers' racially biased beliefs (racial, cultural, and ethnic minorities) and exploring in-service teachers' classroom practices that encourage social equality and promote diversity.

\section{Conclusion}

Diverse student needs in the classroom, as well as student demographics, continue to change. This presents a challenge for in-service teachers to meet the demand of all students in the classroom. Diverse students have different experiences culturally and academically, and their way of learning and perceiving the world should not count as a weakness, but rather as a strength. Student achievement disparities among Whites and minority groups, socioeconomically disadvantaged, and English Language Learners (ELL) are persistent and common (Hachfeld et al., 2015; McFarland et al., 2018; Musu-Gillete et al., 2016). The causes of this disparity in academic student success are highly complex. It includes school-based elements like traditional classrooms that promote segregation, strong teacher bias on diversity as well as culturally diverse teacher training, and ethnic discrimination among teachers and students (Anthony-Stevens et al., 2017; Colgren \& Sappington, 2015; Murdock \& Hamel, 2016; Pezzetti, 2017). Achievement gaps have a profound impact on students and their individual expectations of being accepted, understood, and valued by their teachers and peers. Students might not feel comfortable at school or remain optimistic about their education. The level of uncertainty and anxiety intensifies for students. However, if educators interact with their students by making the environment in the classroom feel inclusive and secure, the learning environment can positively impact the academic achievement of the students.

\section{Conflicts of Interest}

The authors declare no conflicts of interest regarding the publication of this paper. 


\section{References}

Anthony-Stevens, V., Gehlken, E., Jones, C., Day, S., \& Gussenhoven, S. (2017). 'I Am Assumed to Be Someone Who Doesn't Have to Deal with Diversity': Countering the Denial of Diversity in Rural Teacher Education. Multicultural Education Review, 9, 270-288. https://doi.org/10.1080/2005615X.2017.1383813

Banerjee, N. (2018). Effects of Teacher-Student Ethnoracial Matching and Overall Teacher Diversity in Elementary Schools on Educational Outcomes. Journal of Research in Childhood Education, 32, 94-118. https://doi.org/10.1080/02568543.2017.1393032

Bonner, P. J., Warren, S. R., \& Jiang, Y. H. (2018). Voices from Urban Classrooms: Teachers' Perceptions on Instructing Diverse Students and Using Culturally Responsive Teaching. Education and Urban Society, 50, 697-726. https://doi.org/10.1177/0013124517713820

Brown-Jeffy, S., \& Cooper, J. E. (2011). Toward a Conceptual Framework of Culturally Relevant Pedagogy: An Overview of the Conceptual and Theoretical Literature. Teacher Education Quarterly, 38, 65-84. http://www.jstor.org/stable/23479642

Byrd, C. M. (2016). Does Culturally Relevant Teaching Work? An Examination from Student Perspectives. SAGE Open, 6, No. 3. https://doi.org/10.1177/2158244016660744

Change Kids Lives (2019). Culturally Responsive Teaching: 5 Essential Resources. http://www.changekidslives.org/lists-culturally-responsive-teaching

Chenail, R. (2012). Conducting Qualitative Data Analysis: Qualitative Data Analysis as a Metaphoric Process. The Qualitative Report, 17, 248-253. http://www.nova.edu/ssss/QR/QR17-1/chenail-metaphor.pdf

Christ, T., \& Sharma, S. A. (2018). Searching for Mirrors: Preservice Teachers' Journey toward More Culturally Relevant Pedagogy. Reading Horizons, 57, 55-73.

Coghlan, A., \& Filo, K. (2013). Using Constant Comparison Method and Qualitative Data to Understand Participants' Experiences at the Nexus of Tourism, Sport and Charity Events. Tourism Management, 35, 122-131.

https://doi.org/10.1016/j.tourman.2012.06.007

Colgren, C., \& Sappington, N. E. (2015). Closing the Achievement Gap Means Transformation. NCPEA Education Leadership Review of Doctoral Research, 2, 24-33.

https://files.eric.ed.gov/fulltext/EJ1105741.pdf

Dozier, C., Johnston, P. H., \& Rogers, R. (2006). Critical Literacy/Critical Teaching: Tools for Preparing Responsive Teachers. Teachers College Press

Etikan, I. (2016). Comparison of Convenience Sampling and Purposive Sampling. American Journal of Theoretical and Applied Statistics, 5, 1-4.

https://www.researchgate.net/publication/304339244 Comparison of Convenience S ampling and Purposive Sampling https://doi.org/10.11648/j.ajtas.20160501.11

Farinde-Wu, A., Glover, C. P., \& Williams, N. N. (2017). It's Not Hard Work; It's Heart Work: Strategies of Effective, Award-Winning Culturally Responsive Teachers. The Urban Review, 49, 279-299. https://doi.org/10.1007/s11256-017-0401-5

Flores, O. J. (2018). (Re)Constructing the Language of the Achievement Gap to an Opportunity Gap: The Counternarratives of Three African American Women School Leaders. Journal of School Leadership, 28, 344-373.

https://doi.org/10.1177/105268461802800304

Forghani-Arani, N., Cerna, L., \& Bannon, M. (2019). The Lives of Teachers in Diverse Classrooms. Organisation for Economic Cooperation and Development (OECD). 
Gershenson, S., Hart, C. M. D., Hyman, J., Lindsay, C. A., \& Papageorge, N. W. (2018). The Long-Run Impact of Same-Race Teachers. NBER.

https://www.nber.org/system/files/working papers/w25254/w25254.pdf

Glaser, B. (1965). The Constant Comparative Method of Qualitative Analysis. Social Problems, 12, 436-445. https://doi.org/10.2307/798843

Hachfeld, A., Hahn, A., Schroeder, S., Anders, Y., \& Kunter, M. (2015). Should Teachers Be Colorblind? How Multicultural and Egalitarian Beliefs Differentially Relate to Aspects of Teachers' Professional Competence for Teaching in Diverse Classrooms. Teaching and Teacher Education, 48, 44-55. https://doi.org/10.1016/j.tate.2015.02.001

Harding-DeKam, J. L. (2014). Defining Culturally Responsive Teaching: The Case of Mathematics. Cogent Education, 1, Article ID: 972676.

https://doi.org/10.1080/2331186X.2014.972676

Hernandez, C., \& Shroyer, M. G. (2017). The Use of Culturally Responsive Teaching Strategies among Latina/o Student Teaching Interns during Science and Mathematics Instruction of CLD Students. Journal of Science Teacher Education, 28, 367-387. https://doi.org/10.1080/1046560X.2017.1343605

Hodge, S. R., \& Collins, F. G. (2019). Physical Education Teachers' Understandings of Culturally Relevant Pedagogy in Teaching Black Male Students. Multicultural Learning and Teaching, 14, Article ID: 20150016. https://doi.org/10.1515/mlt-2015-0016

Holt, S. B., \& Gershenson, S. (2015). The Impact of Demographic Representation on Absences and Suspensions. Policy Studies Journal, 47, 1069-1099.

Janks, H. (2010). Language, Power and Pedagogies. In N. H. Hornberger, \& S. L. McKay (Eds.), Sociolinguistics and Language Education (pp. 40-61). Multilingual Matters. https://doi.org/10.21832/9781847692849-004

King, J. B., McIntosh, A., \& Bell-Ellwanger, J. (2016). The State of Racial Diversity in the Educator Workforce. U.S. Department of Education, Office of Planning, Evaluation and Policy Development, Policy and Program Studies Service.

Kuby, C. R. (2013). Critical Literacy in the Early Childhood Classroom: Unpacking Histories, Unlearning Privilege. Teachers College Press.

Ladson-Billings, G. (1990). Like Lightning in a Bottle: Attempting to Capture the Pedagogical Excellence of Successful Teachers of Black Students. International Journal of Qualitative Studies in Education, 3, 335-344. https://doi.org/10.1080/0951839900030403

Ladson-Billings, G. (1994). What We Can Learn from Multicultural Education Research. Educational Leadership, 51, 22-26.

Ladson-Billings, G. (1995). Toward a Theory of Culturally Relevant Pedagogy. American Educational Research Journal, 32, 465-491. https://doi.org/10.3102/00028312032003465

Ladson-Billings, G. (2014). Culturally Relevant Pedagogy 2.0: A.K.A. the Remix. Harvard Educational Review, 84, 74-84. https://doi.org/10.17763/haer.84.1.p2rj131485484751

Lambeth, D. T., \& Smith, A. M. (2016). Pre-Service Teachers' Perceptions of Culturally Responsive Teacher Preparation. The Journal of Negro Education, 85, 46-58. https://doi.org/10.7709/jnegroeducation.85.1.0046

Larson, K. E., Pas, E. T., Bradshaw, C. P., Rosenberg, M. S., \& Day-Vines, N. L. (2018). Examining How Proactive Management and Culturally Responsive Teaching Relate to Student Behavior: Implications for Measurement and Practice. School Psychology Review, 47, 153-166. https://doi.org/10.17105/SPR-2017-0070.V47-2

Leech, N. L., \& Onwuegbuzie, A. J. (2007). An Array of Qualitative Data Analysis Tools: A Call for Data Analysis Triangulation. School Psychology Quarterly, 22, 557-584. 
https://doi.org/10.1037/1045-3830.22.4.557

Lindsay, C. A., \& Hart, C. M. D. (2017). Exposure to Same-Race Teachers and Student Disciplinary Outcomes for Black Students in North Carolina. Educational Evaluation and Policy Analysis, 39, 485-510. https://doi.org/10.3102/0162373717693109

Lopez, F. A. (2016). Culturally Responsive Pedagogies in Arizona and Latino Students' Achievement. Teacher College Record, 118, 1-42. https://doi.org/10.1177/016146811611800503

Lowery, C. L. (2018). An Autoethnography of Culturally Relevant Leadership as Moral Practice: Lived Experiences through a Scholar-Practitioner Lens. The Qualitative Report, 23, 3036-3053.

Mackay, H., \& Strickland, M. J. (2018). Exploring Culturally Responsive Teaching and Student-Created Videos in an At-Risk Middle School Classroom. Middle Grades Review, 4, Article No. 7.

Maguire, M., \& Delahunt, B. (2017) Doing a Thematic Analysis: A Practical, Step-by-Step Guide for Learning and Teaching Scholars. All Ireland Journal of Higher Education (AISHE-J), 9, 3351. https://ojs.aishe.org/index.php/aishe-j/article/view/335/553

Maher, C., Hadfield, M., Hutchings, M., \& de Eyto, A. (2018). Ensuring Rigor in Qualitative Data Analysis: A Design Research Approach to Coding Combining NVivo with Traditional Material Methods. International Journal of Qualitative Methods, 17, No. 1. https://doi.org/10.1177/1609406918786362

McFarland, J., Hussar, B., Wang, X., Zhang, J., Wang, K., Rathbun, A., \& Mann, F. B. (2018). The Condition of Education 2018. National Center for Education Statistics.

Murdock, D., \& Hamel, E. (2016). I Would Quit My Job: Unpacking Preservice Teachers' Perceptions of Cultural Diversity. International Journal of Critical Pedagogy, 7, 85-106.

Murnane, R. J. (2007). Improving the Education of Children Living in Poverty. The Future of Children, 17, 161-182. https://doi.org/10.1353/foc.2007.0019

Musu-Gillete, L., Robinson, J., MacFarland, J., KewalRamani, A., Zhang, A., \& Wilkinson-Flicker, S. (2016). Status and Trends in the Education of Racial and Ethnic Groups 2016. National Center for Education Statistics.

Nasir, N. I. S. (2002). Identity, Goals, and Learning: Mathematics in Cultural Practice. Mathematical Thinking and Learning, 4, 213-247. https://doi.org/10.1207/S15327833MTL04023 6

NEA (2018). Students Affected by Achievement Gaps. Washington DC. http://www.nea.org/home/20380.htm

Pappamihiel, N. E., \& Moreno, M. (2011). Retaining Latino Students: Culturally Responsive Instruction in Colleges and Universities. Journal of Hispanic Higher Education, 10, 331-344. https://doi.org/10.1177/1538192711410602

Pezzetti, K. (2017). 'I'm Not Racist; My High School Was Diverse!' White Preservice Teachers Deploy Diversity in the Classroom. Whiteness and Education, 2, 131-147. https://doi.org/10.1080/23793406.2017.1362944

Shevalier, R., \& McKenzie, B. A. (2012). Culturally Responsive Teaching as an Ethics and Care Based Approach to Urban Education. Urban Education, 47, 1086-1105. https://doi.org/10.1177/0042085912441483

Stuckey, H. L. (2015). The Second Step in Data Analysis: Coding Qualitative Research Data. Journal of Social Health and Diabetes, 3, 7-10. https://doi.org/10.4103/2321-0656.140875

Sutcher, L., Darling-Hammond, L., \& Carver-Thomas, D. (2016). A Coming Crisis in Teaching? Teacher Supply, Demand, and Shortages in the U.S. Palo Alto, CA: Learning 
Policy Institute. https://doi.org/10.54300/247.242

Valeriu, D. (2017). Teacher Training for Multicultural Classroom Teaching. Euromentor Journal, 8, 71-81.

Vescio, V. (2016). An Equal Chance at Success: Culturally Responsive Teaching Practices Address Students' Differing Needs. The Learning Forward Journal, 37, 18-22. https://learningforward.org/journal/october-2016-issue/an-equal-chance-at-success/

Vesely, C. K., Brown, B. E., \& Mehta, S. (2017). Developing Cultural Humility through Experiential Learning: How Home Visits Transform Early Childhood Pre-Service Educators' Attitudes for Engaging Families. Journal of Early Childhood Teacher Education, 38, 242-258. https://doi.org/10.1080/10901027.2017.1345805

Wachira, P., \& Mburu, J. (2019). Culturally Responsive Mathematics Teaching and Constructivism: Preparing Teachers for Diverse Classrooms. Multicultural Learning and Teaching, 14, Article ID: 20160023. https://doi.org/10.1515/mlt-2016-0023

Zamawe, F. C. (2015). The Implication of Using NVivo Software in Qualitative Data Analysis: Evidence-Based Reflections. Malawi Medical Journal, 27, 13-15.

https://doi.org/10.4314/mmj.v27i1.4 


\section{Appendix A: Interview Protocol}

The following are guided questions that were used in individual interviews.

Introduction and Demographic Information:

What is your gender?

What is your age range?

$21-29$

$30-39$

$40-49$

$50-59$

$60-69$

69 plus

How many years have you been teaching?

What is your ethnicity?

Interview Question:

How would you describe and identify with culturally relevant teaching?

How do you perceive culturally relevant teaching in relation to your classroom environment and the local community your school serves?

How has the school or district prepared you with resources that are developmentally appropriate and meaningful to all students?

Describe how your district or school has supported or influenced your preparation for teaching the diverse cultures of students in your classroom.

Describe ways in which you have been supported in developing relationships with your students?

Describe resources and training that have helped you understand and utilize culturally relevant teaching.

What lessons, projects, or special events have you helped plan that demonstrate culturally relevant teaching?

What practices or strategies do you use to implement culturally relevant teaching as appropriate to the developmental stage of the students in your classroom?

Describe how you create an environment to encourage the success of every child.

How has culturally relevant teaching influenced how you develop relationships with your students? 